\title{
Finite element analysis in geotechnical engineering
}

\section{Application}

David M. Potts and Lidija Zdravković

Imperial College of Science, Technology and Medicine

With contributions from:

Trevor I. Addenbrooke

Kelvin G. Higgins

Nebojša Kovačević

\section{$\mathbf{T}$ ThomasTelford}


Published by Thomas Telford Publishing, Thomas Telford Ltd, 1 Heron Quay, London E14 4JD.

URL: http://www.thomastelford.com

Distributors for Thomas Telford books are

USA: ASCE Press, 1801 Alexander Bell Drive, Reston, VA 20191-4400, USA

Japan: Maruzen Co. Ltd, Book Department, 3-10 Nihonbashi 2-chome, Chuo-ku, Tokyo 103

Australia: DA Books and Journals, 648 Whitehorse Road, Mitcham 3132, Victoria

First published 2001

Also available from Thomas Telford Books

Finite element analysis in geotechnical engineering: theory. ISBN 0727727532

A catalogue record for this book is available from the British Library

ISBN: 0727727834

(C) David M. Potts and Lidija Zdravković, and Thomas Telford Limited, 2001

All rights, including translation, reserved. Except as permitted by the Copyright, Designs and Patents Act 1988, no part of this publication may be reproduced, stored in a retrieval system or transmitted in any form or by any means, electronic, mechanical, photocopying or otherwise, without the prior written permission of the Publishing Director, Thomas Telford Publishing, Thomas Telford Ltd, 1 Heron Quay, London E14 4JD.

This book is published on the understanding that the author are solely responsible for the statements made and opinions expressed in it and that its publication does not necessarily imply that such statements and/or opinions are or reflect the views or opinions of the publishers. While every effort has been made to ensure that the statements made and the opinions expressed in this publication provide a safe and accurate guide, no liability or responsibility can be accepted in this respect by the authors or publishers. 


\section{Contents}

Preface $\quad x i$

Authorship $\quad x v i$

Acknowledgements $\quad$ xvi

1. Obtaining geotechnical parameters 1

1.1 Synopsis

1.2 Introduction

1.3 Laboratory tests 2

1.3.1 Introduction 2

1.3.2 Oedometer test 3

1.3.3 Triaxial test 6

1.3.4 True triaxial test 11

$\begin{array}{lll}1.3 .5 & \text { Direct shear test } & 12\end{array}$

$\begin{array}{lll}\text { 1.3.6 Simple shear test } & 14\end{array}$

1.3.7 Ring shear test 15

1.3.8 Hollow cylinder test 16

$\begin{array}{ll}1.3 .9 & \text { Directional shear cell } \\ 1.3 .10 & 20\end{array}$

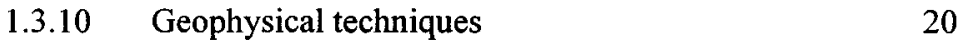

1.3.11 Permeameters 22

$\begin{array}{lll}1.4 & \text { In-situ tests } & 23\end{array}$

$\begin{array}{lll}\text { 1.4.1 Introduction } & 23\end{array}$

1.4.2 Standard penetration test (SPT) 23

$\begin{array}{lll}1.4 .3 & \text { Cone penetration test (CPT) } & 27\end{array}$

1.4.4 Pressuremeter testing 30

$\begin{array}{lll}1.4 .5 & \text { The plate loading test } & 32\end{array}$

1.4.6 Pumping tests 35

1.5 Summary 35

2. Tunnels 38

$\begin{array}{lll}2.1 & \text { Synopsis } & 38\end{array}$

$\begin{array}{lll}2.2 & \text { Introduction } & 38\end{array}$

$\begin{array}{ll}2.3 & \text { Tunnel construction }\end{array}$ 
ii / Finite element analysis in geotechnical engineering: Application

$\begin{array}{lll}2.3 .1 & \text { Introduction } & 39\end{array}$

2.3.2 Open faced shield tunnelling 40

2.3.3 Tunnel Boring Machines (TBM), including slurry shields and Earth Pressure Balance (EPB) tunnelling 40

2.3.4 The sprayed concrete lining (SCL) method 41

2.3.5 Ground response to tunnel construction 41

2.4 Simulation of the construction process 43

2.4.1 Introduction 43

2.4.2 Setting up the initial conditions 44

2.4.3 Important boundary conditions 45

2.4.4 Modelling tunnel excavation 45

2.4.5 Modelling the tunnel lining 48

2.5 Modelling time dependent behaviour 52

2.5.1 Introduction 52

2.5.2 Setting up the initial conditions 52

2.5.3 Hydraulic boundary conditions 54

2.5.4 Permeability models 55

2.5.5 A parametric study of the effect of permeable and impermeable tunnel linings $\quad 57$

2.6 Choice of soil model $\quad 59$

2.6.1 Introduction 59

2.6.2 Results from a parametric study 59

2.6.3 Devices for improving the surface settlement
prediction

2.7 Interaction analysis 63

2.7.1 The influence of building stiffness on tunnel-induced ground movements 63

2.7.2 The Treasury building - a case study 66

$\begin{array}{ll}2.7 .3 & \text { Twin tunnel interaction } \\ \end{array}$

$\begin{array}{lll}2.8 & \text { Summary } & 72\end{array}$

3. Earth retaining structures $\quad 74$

$\begin{array}{lll}3.1 & \text { Synopsis } & 74\end{array}$

$\begin{array}{lll}3.2 & \text { Introduction } & 74\end{array}$

3.3 Types of retaining structure 75

3.3.1 Introduction 75

$\begin{array}{ll}\text { 3.3.2 Gravity walls } & 75\end{array}$

3.3.3 Reinforced/anchored earth wall $\quad 76$

3.3.4 Embedded walls 76

3.4 General considerations $\quad 77$

3.4.1 Introduction 77

$\begin{array}{lll}3.4 .2 & \text { Symmetry } & 77\end{array}$

3.4.3 Geometry of the finite element model 79

3.4.4 Support systems $\quad 82$ 
3.4.5 Choice of constitutive models 84

3.4.5.1 Structural components $\quad 84$

3.4.5.2 Soil 85

3.4.6 Initial ground conditions 88

3.4.6.1 General 88

3.4.6.2 'Greenfield' conditions $\quad 88$

3.4.6.3 Modified initial soil stresses $\quad 89$

3.4.7 Construction method and programme 91

3.4.7.1 General 91

3.4.7.2 Construction method 91

3.4.7.3 Time related movements $\quad 92$

3.4.7.4 Ground water control 93

3.5 Gravity walls 93

3.5.1 Introduction 93

3.5.2 Earth pressure due to compaction 94

3.5.3 Finite element analysis 95

3.6 Reinforced earth walls 96

3.6.1 Introduction 96

$\begin{array}{lr}\text { 3.6.2 Finite element analysis } & 99\end{array}$

3.7 Embedded walls 103

$\begin{array}{lll}3.7 .1 & \text { Introduction } & 103\end{array}$

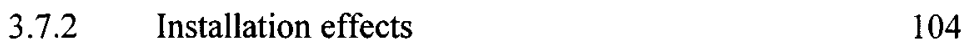

3.7.2.1 General 104

3.7.2.2 Field measurements 104

3.7.2.3 Analysis 105

3.7.2.4 Comments 106

$\begin{array}{ll}\text { 3.7.3 Modelling of walls } & 107\end{array}$

$\begin{array}{lll}\text { 3.7.3.1 Element type } & 107\end{array}$

$\begin{array}{ll}\text { 3.7.3.2 Wall stiffness } & 109\end{array}$

3.7.3.3 Interface behaviour 111

3.7.3.4 Wall permeability 111

$\begin{array}{lll}3.7 .4 & \text { Support systems } & 112\end{array}$

$\begin{array}{ll}\text { 3.7.4.1 Introduction } & 112\end{array}$

$\begin{array}{lll}3.7 .4 .2 & \text { Support stiffness } & 112\end{array}$

3.7.4.3 Connection details 113

$\begin{array}{ll}\text { 3.7.4.4 Active support systems } & 114\end{array}$

3.7.4.5 Berms 115

3.7.4.6 Ground anchors 115

$\begin{array}{ll}\text { 3.7.4.7 Relieving slabs } & 116\end{array}$

3.7.5 Long term behaviour and post construction effects 118

$\begin{array}{ll}3.7 .6 \quad \text { Adjacent structures } & 119\end{array}$

$\begin{array}{lll}3.8 & \text { Summary } & 122\end{array}$

Appendix III.1 123 
iv / Finite element analysis in geotechnical engineering: Application

4. Cut slopes

4.1 Synopsis 125

$\begin{array}{lll}4.2 & \text { Introduction } & 125\end{array}$

4.3 'Non-softening' analyses 126

$\begin{array}{lll}4.3 .1 & \text { Introduction } & 126\end{array}$

4.3.2 Cut slopes in stiff 'non-softening' clay 127

$\begin{array}{lll}\text { 4.3.2.1 Introduction } & 127\end{array}$

$\begin{array}{lll}\text { 4.3.2.2 Soil parameters } & 127\end{array}$

4.3.2.3 Finite element analyses 127

$\begin{array}{lll}\text { 4.3.2.4 Results of analyses } & 128\end{array}$

4.3.3 Cut slopes in soft clay 131

4.3.3.1 Introduction 131

4.3.3.2 Soil parameters 132

4.3.3.3 Finite element analyses 136

4.3.3.4 Results of analyses 138

$\begin{array}{lll}4.4 & \text { Progressive failure } & 141\end{array}$

4.5 'Softening' analyses 145

4.5.1 Introduction 145

4.5.2 Choice of constitutive model 146

4.5.3 Implications for convergence 147

4.5.4 Cut slopes in London Clay 147

4.5.4.1 Introduction 147

4.5.4.2 Soil parameters 148

4.5.4.3 Finite element analyses 150

4.5.4.4 Results of a typical analysis $\quad 150$

4.5.4.5 Effect of coefficient of earth

4.5.4.6 Effect of surface boundary suction $\quad 155$

4.5.4.7 Effect of slope geometry 155

4.5.4.8 Effect of surface cracking 156

4.5.4.9 Effect of subsequent changes to slope

4.5.4.10 Further discussion 160

4.6 Construction of cut slope under water 162

$\begin{array}{lll}4.7 & \text { Summary } & 163\end{array}$

$\begin{array}{ll}\text { 5. Embankments } & 166\end{array}$

$\begin{array}{lll}5.1 & \text { Synopsis } & 166\end{array}$

$\begin{array}{lll}5.2 & \text { Introduction } & 166\end{array}$

$\begin{array}{lll}5.3 & \text { Finite element analysis of rockfill dams } & 167\end{array}$

$\begin{array}{lll}5.3 .1 & \text { Introduction } & 167\end{array}$

$\begin{array}{lll}\text { 5.3.2 Typical stress paths } & 167\end{array}$

5.3.3 Choice of constitutive models 168

$\begin{array}{ll}\text { 5.3.3.1 Linear elastic analysis } & 169\end{array}$ 
5.3.3.2 'Power law' models $\quad 169$

5.3.3.3 Hyperbolic model 170

5.3.3.4 K-G model 171

5.3.3.5 Elasto-plastic models 171

5.3.4 Layered analysis, stiffness of the simulated layer and compaction stresses 173

5.3.5 Example: Analysis of Roadford dam 175

5.3.5.1 Introduction 175

5.3.5.2 Material parameters 175

5.3.5.3 Finite element analysis $\quad 177$

5.3.5.4 Comparison with observations $\quad 179$

5.3.6 Example: Analysis of old puddle clay core dams $\quad 180$

5.3.6.1 Introduction 180

5.3.6.2 Dale Dyke dam 181

5.3.6.3 Ramsden dam 183

5.4 Finite element analysis of earth embankments $\quad 185$

$\begin{array}{lll}5.4 .1 & \text { Introduction } & 185\end{array}$

5.4.2 Modelling of earthfill 186

5.4.3 Example: Road embankments on London Clay $\quad 186$

5.4.3.1 Introduction 186

$\begin{array}{ll}\text { 5.4.3.2 Material properties } & 187\end{array}$

5.4.3.3 Finite element analyis $\quad 188$

5.4.4 Example: Failure of Carsington embankment $\quad 189$

5.4.4.1 Introduction 189

5.4.4.2 Material parameters and soil model used 190

5.4.4.3 Finite element analysis 191

5.4.4.4 Original Carsington section 191

5.4.4.5 Effect of the core geometry on

5.4.4.6 Effect of berm in improving the stability 193

5.5 Finite element analysis of embankments on soft clay 194

$\begin{array}{lll}5.5 .1 & \text { Introduction } & 194\end{array}$

5.5.2 Typical soil conditions 195

5.5.3 Choice of constitutive model 196

5.5.4 Modelling soil reinforcement 198

5.5.5 Example: Effect of a surface crust 198

5.5.5.1 Introduction 198

5.5.5.2 Soil conditions 198

5.5.5.3 Finite element analysis 199

5.5.5.4 Results 200

5.5.6 Example: Effect of reinforcement 200

5.5.6.1 Introduction 200

5.5.6.2 Soil conditions 201

5.5.6.3 Results 201 
vi / Finite element analysis in geotechnical engineering: Application

5.5.7 Example: Staged construction 202

5.5.7.1 Introduction 202

$\begin{array}{ll}\text { 5.5.7.2 Soil conditions } & 203\end{array}$

5.5.7.3 Finite element analysis 204

5.5.7.4 Results 205

5.5.8 Example: Effect of anisotropic soil behaviour 206

5.5.8.1 Introduction 206

5.5.8.2 Geometry 206

5.5.8.3 Soil conditions 207

5.5.8.4 Finite element analysis 207

5.5.8.5 Results 208

$\begin{array}{lll}5.6 & \text { Summary } & 211\end{array}$

$\begin{array}{lr}\text { 6. Shallow foundations } & 214\end{array}$

$\begin{array}{ll}6.1 \text { Synopsis } & 214\end{array}$

$\begin{array}{ll}6.2 \text { Introduction } & 214\end{array}$

$\begin{array}{lll}6.3 & \text { Foundation types } & 215\end{array}$

$\begin{array}{lll}6.3 .1 & \text { Surface foundations } & 215\end{array}$

$\begin{array}{ll}6.3 .2 & \text { Shallow foundations } \\ & 215\end{array}$

$\begin{array}{ll}6.4 & \text { Choice of soil model } \\ 6.515\end{array}$

6.5 Finite element analysis of surface foundations 216

$\begin{array}{lll}6.5 .1 & \text { Introduction } & 216\end{array}$

$\begin{array}{ll}6.5 .2 & \text { Flexible foundations } \\ 6.5 .3 & 218\end{array}$

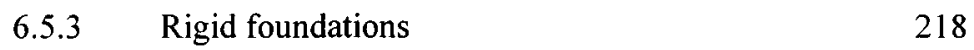

6.5.4 Examples of vertical loading 219

6.5.4.1 Introduction 219

6.5.4.2 Strip footings on undrained clay 219

6.5.4.3 Effect of footing shape on the bearing capacity of undrained clay 223

6.5.4.4 Strip footings on weightless drained soil 225

6.5.4.5 Strip footings on a drained soil 227

6.5.4.6 Circular footings on a weightless drained soil 230

6.5.4.7 Circular footings on a drained soil 232

6.5.5 Undrained bearing capacity of non-homogeneous
clay

6.5.5.1 Introduction 233

6.5.5.2 Constitutive model 234

6.5.5.3 Geometry and boundary conditions 236

6.5.5.4 Failure mechanisms 236

$\begin{array}{ll}\text { 6.5.6 Undrained bearing capacity of pre-loaded strip } & \\ & \text { foundations on clay }\end{array}$

6.5.6.1 Introduction 238

6.5.6.2 Constitutive model 239 
6.5.6.3 Geometry and boundary conditions 240

6.5.6.4 Results of the analyses 240

6.5.6.5 Concluding remarks 243

6.5.7 Effect of anisotropic strength on bearing capacity 243

6.5.7.1 Introduction 243

6.5.7.2 Soil behaviour 244

6.5.7.3 Behaviour of strip footings 246

6.5.7.4 Behaviour of circular footings 247

6.6 Finite element analysis of shallow foundations 248

$\begin{array}{lll}\text { 6.6.1 Introduction } & 248\end{array}$

6.6.2 Effect of foundation depth on undrained bearing capacity 248

6.6.3 Example: The leaning Tower of Pisa 252

6.6.3.1 Introduction 252

6.6.3.2 Details of the Tower and ground profile 253

6.6.3.3 History of construction 254

6.6.3.4 History of tilting 255

6.6.3.5 The motion of the Tower foundations 256

6.6.3.6 Stability of tall towers 256

6.6.3.7 Soil properties 259

6.6.3.8 Finite element analysis 263

6.6.3.9 Simulation of the history of inclination 265

6.6.3.10 Temporary counterweight 267

6.6.3.11 Observed behaviour during application
of the counterweight

6.6.3.12 Permanent stabilisation of the Tower 271

6.6.3.13 Soil extraction 271

6.6.3.14 The response of the Tower to

6.6.3.15 Comments 276

$\begin{array}{lll}6.7 & \text { Summary } & 278\end{array}$

7. Deep foundations 280

7.1 Synopsis 280

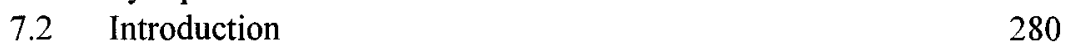

7.3 Single piles 282

7.3.1 Introduction 282

7.3.2 Vertical loading 282

7.3.3 Lateral loading 287

7.4 Pile group behaviour 289

$\begin{array}{ll}\text { 7.4.1 Introduction } & 289\end{array}$

7.4.2 Analysis of a pile group 291

$\begin{array}{lll}7.4 .3 & \text { Superposition } & 291\end{array}$

7.4.3.1 Simple superposition 292 
viii / Finite element analysis in geotechnical engineering: Application

7.4.3.2 Pile displacements with depth 293

7.4.4 Load distribution within a pile group 294

7.4.4.1 Obtaining an initial trial division of the applied loads 296

7.4.4.2 Evaluating pile head displacements 297

7.4.4.3 Checking the rigid pile cap criterion 297

7.4.5 Pile group design 298

7.4.5.1 Matrix formulation of the pile group response 298

7.4.5.2 Superposition of loads 299

7.4.5.3 Evaluating the solution displacements and rotations 302

7.4.6 Magnus 304

7.4.6.1 Introduction 304

7.4.6.2 Soil properties and initial conditions 304

7.4.6.3 Finite element analyses 308

7.4.6.4 Design of Magnus foundations 309

7.4.6.5 Environmental loading 314

$\begin{array}{lll}7.5 & \text { Bucket foundations } & 317\end{array}$

$\begin{array}{ll}\text { 7.5.1 Introduction } & 317\end{array}$

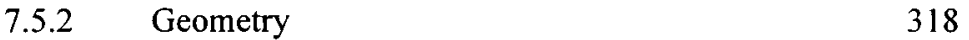

7.5.3 Finite element analysis 318

7.5.4 Modelling of the interface between top cap and soil 320

$\begin{array}{lll}7.5 .5 & \text { Isotropic study } & 321\end{array}$

7.5.5.1 Soil conditions 321

7.5.5.2 Parametric studies 322

7.5.5.3 Results 322

7.5.6 Anisotropic study 326

7.5.6.1 Introduction 326

7.5.6.2 Results 326

$\begin{array}{lll}\text { 7.5.7 Suction anchors } & 327\end{array}$

$\begin{array}{ll}\text { 7.5.7.1 Introduction } & 327\end{array}$

$\begin{array}{ll}\text { 7.5.7.2 Geometry } 327 & 327\end{array}$

7.5.7.3 Results 329

$\begin{array}{lll}7.6 & \text { Summary } & 329\end{array}$

8. Benchmarking 332

8.1 Synopsis 332

8.2 Definitions 332

8.3 Introduction 333

8.4 Causes of errors in computer calculations 334

8.5 Consequences of errors 335

8.6 Developers and users 336

8.6.1 Developers 336 
$\begin{array}{lll}\text { 8.6.2 Users } & 337\end{array}$

8.7 Techniques used to check computer calculations 339

$\begin{array}{lll}8.8 & \text { Benchmarking } & 339\end{array}$

$\begin{array}{lll}\text { 8.8.1 General } & 339\end{array}$

8.8.2 Standard benchmarks $\quad 340$

8.8.3 Non-standard benchmarks 341

8.9 The INTERCLAY II project 341

8.10 Examples of benchmark problems - Part I 342

8.10.1 General 342

8.10.2 Example 1: Analyses of an ideal triaxial test 343

8.10.3 Example 2: Analysis of a thick cylinder 344

8.10.4 Example 3: Analyses of an advancing tunnel

8.10.5 Example 4: Analysis of a shallow waste disposal 348

8.10.6 Example 5: Simplified analysis of a shallow waste 351

8.11 Examples of benchmark problems - Part II

(German Society for Geotechnics benchmarking exercise) 353

$\begin{array}{lll}\text { 8.11.1 Background } & 353\end{array}$

8.11.2 Example 6: Construction of a tunnel 353

8.11.3 Example 7: Deep excavation 355

8.11.4 General comments 356

8.12 Summary 357

Appendix VIII.1 Specification for Example 1: Analyses of an idealised triaxial test $\quad 358$

$\begin{array}{lll}\text { VIII.1.1 Geometry } & 358\end{array}$

VIII.1.2 Material properties and initial stress conditions 358

VIII.1.3 Loading conditions 358

Appendix VIII.2 Specification for Example 2: Analysis of a thick cylinder $\quad 358$

$\begin{array}{lll}\text { VIII.2.1 Geometry } & 358\end{array}$

VIII.2.2 Material properties 358

VIII.2.3 Loading conditions 359

Appendix VIII.3 Specification for Example 3: Analysis of an advancing tunnel heading $\quad 359$

$\begin{array}{lll}\text { VIII.3.1 Geometry } & 359\end{array}$

VIII.3.2 Material properties $\quad 359$

VIII.3.3 Loading conditions $\quad 359$

Appendix VIII.4 Specification for Example 4: Analysis of a shallow waste disposal $\quad 360$

$\begin{array}{lll}\text { VIII.4.1 Geometry } & 360\end{array}$

VIII.4.2 Material properties $\quad 360$

VIII.4.3 Loading conditions 361

Appendix VIII.5 Specification for Example 5: Simplified analysis of a shallow waste disposal 
$x$ / Finite element analysis in geotechnical engineering: Application

VIII.5.1 Geometry 361

VIII.5.2 Material properties 361

VIII.5.3 Loading conditions 361

VIII.5.4 Additional boundary conditions 362

Appendix VIII.6 Specification for Example 6: Construction of a tunnel 362

VIII.6.1 Geometry 362

VIII.6.2 Material properties 362

Appendix VIII.7 Specification for Example 7: Deep excavation 362

VIII.7.1 Geometry 362

VIII.7.2 Material properties $\quad 362$

VIII.7.3 Construction stages 363

9. Restrictions and pitfalls 364

9.1 Synopsis 364

9.2 Introduction 364

9.3 Discretisation errors 365

9.4 Numerical stability of zero thickness interface elements 368

9.4.1 Introduction 368

$\begin{array}{lll}9.4 .2 & \text { Basic theory } & 368\end{array}$

9.4.3 Ill-conditioning 370

9.4.4 Steep stress gradients 373

9.5 Modelling of structural members in plane strain analysis 376

9.5.1 Walls 376

$\begin{array}{lll}\text { 9.5.2 Piles } & 377\end{array}$

9.5.3 Ground anchors 378

9.5.4 Structural members in coupled analyses $\quad 380$

9.5.5 Structural connections 38.0

9.5.6 Segmental tunnel linings 381

9.6 Use of the Mohr-Coulomb model for undrained analysis 382

9.7 Influence of the shape of the yield and plastic potential surfaces in the deviatoric plane $\quad 384$

9.8 Using critical state models in undrained analysis 386

9.9 Construction problems 387

9.10 Removal of prescribed degrees of freedom 388

9.11 Modelling underdrainage $\quad 389$

$\begin{array}{lll}9.12 \text { Summary } & 394\end{array}$

$\begin{array}{ll}\text { References } & 396\end{array}$

$\begin{array}{ll}\text { List of symbols } & 410\end{array}$

$\begin{array}{ll}\text { Index } & 415\end{array}$ 


\section{Preface}

While the finite element method has been used in many fields of engineering practice for over thirty years, it is only relatively recently that it has begun to be widely used for analysing geotechnical problems. This is probably because there are many complex issues which are specific to geotechnical engineering and which have only been resolved relatively recently. Perhaps this explains why there are few books which cover the application of the finite element method to geotechnical engineering.

For over twenty years we, at Imperial College, have been working at the leading edge of the application of the finite element method to the analysis of practical geotechnical problems. Consequently, we have gained enormous experience of this type of work and have shown that, when properly used, this method can produce realistic results which are of value to practical engineering problems. Because we have written all our own computer code, we also have an in-depth understanding of the relevant theory.

Based on this experience we believe that, to perform useful geotechnical finite element analysis, an engineer requires specialist knowledge in a range of subjects. Firstly, a sound understanding of soil mechanics and finite element theory is required. Secondly, an in-depth understanding and appreciation of the limitations of the various constitutive models that are currently available is needed. Lastly, users must be fully conversant with the manner in which the software they are using works. Unfortunately, it is not easy for a geotechnical engineer to gain all these skills, as it is vary rare for all of them to be part of a single undergraduate or postgraduate degree course. It is perhaps, therefore, not surprising that many engineers, who carry out such analyses and/or use the results from such analyses, are not aware of the potential restrictions and pitfalls involved.

This problem was highlighted four years ago when we gave a four day course on numerical analysis in geotechnical engineering. Although the course was a great success, attracting many participants from both industry and academia, it did highlight the difficulty that engineers have in obtaining the necessary skills required to perform good numerical analysis. In fact, it was the delegates on this course who urged us, and provided the inspiration, to write this book.

The overall objective of the book is to provide the reader with an insight into the use of the finite element method in geotechnical engineering. More specific aims are: 
- To present the theory, assumptions and approximations involved in finite element analysis;

- To describe some of the more popular constitutive models currently available and explore their strengths and weaknesses;

- To provide sufficient information so that readers can assess and compare the capabilities of available commercial software;

- To provide sufficient information so that readers can make judgements as to the credibility of numerical results that they may obtain, or review, in the future;

- To show, by means of practical examples, the restrictions, pitfalls, advantages and disadvantages of numerical analysis.

The book is primarily aimed at users of commercial finite element software both in industry and in academia. However, it will also be of use to students in their final years of an undergraduate course, or those on a postgraduate course in geotechnical engineering. A prime objective has been to present the material in the simplest possible way and in manner understandable to most engineers. Consequently, we have refrained from using tensor notation and have presented all theory in terms of conventional matrix algebra.

When we first considered writing this book, it became clear that we could not cover all aspects of numerical analysis relevant to geotechnical engineering. We reached this conclusion for two reasons. Firstly, the subject area is so vast that to adequately cover it would take many volumes and, secondly, we did not have experience with all the different aspects. Consequently, we decided only to include material which we felt we had adequate experience of and that was useful to a practising engineer. As a result we have concentrated on static behaviour and have not considered dynamic effects. Even so, we soon found that the material we wished to include would not sensibly fit into a single volume. The material has therefore been divided into theory and application, each presented in a separate volume.

Volume 1 concentrates on the theory behind the finite element method and on the various constitutive models currently available. This is essential reading for any user of a finite element package as it clearly outlines the assumptions and limitations involved. Volume 2 concentrates on the application of the method to real geotechnical problems, highlighting how the method can be applied, its advantages and disadvantages, and some of the pitfalls. This is also essential reading for a user of a software package and for any engineer who is commissioning and/or reviewing the results of finite element analyses.

Volume 1 of this book consists of twelve chapters. Chapter 1 considers the general requirements of any form of geotechnical analysis and provides a framework for assessing the relevant merits of the different methods of analysis currently used in geotechnical design. This enables the reader to gain an insight into the potential advantage of numerical analysis over the more 'conventional' approaches currently in use. The basic finite element theory for linear material behaviour is described in Chapter 2. Emphasis is placed on highlighting the 
assumptions and limitations. Chapter 3 then presents the modifications and additions that are required to enable geotechnical analysis to be performed.

The main limitation of the basic finite element theory is that it is based on the assumption of linear material behaviour. Soils do not behave in such a manner and Chapter 4 highlights the important facets of soil behaviour that ideally should be accounted for by a constitutive model. Unfortunately, a constitutive model which can account for all these facets of behaviour, and at the same time be defined by a realistic number of input parameters which can readily be determined from simple laboratory tests, does not exist. Nonlinear elastic constitutive models are presented in Chapter 5 and although these are an improvement over the linear elastic models that were used in the early days of finite element analyses, they suffer severe limitations. The majority of constitutive models currently in use are based on the framework of elasto-plasticity and this is described in Chapter 6. Simple elasto-plastic models are then presented in Chapter 7 and more complex models in Chapter 8.

To use these nonlinear constitutive models in finite element analysis requires an extension of the theory presented in Chapter 2. This is described in Chapter 9 where some of the most popular nonlinear solution strategies are considered. It is shown that some of these can result in large errors unless extreme care is exercised by the user. The procedures required to obtain accurate solutions are discussed.

Chapter 10 presents the finite element theory for analysing coupled problems involving both deformation and pore fluid flow. This enables time dependent consolidation problems to be analysed.

Three dimensional problems are considered in Chapter 11. Such problems require large amounts of computer resources and methods for reducing these are discussed. In particular the use of iterative equation solvers is considered. While these have been used successfully in other branches of engineering, it is shown that, with present computer hardware, they are unlikely to be economical for the majority of geotechnical problems.

The theory behind Fourier Series Aided Finite Element Analysis is described in Chapter 12. Such analysis can be applied to three dimensional problems which possess an axi-symmetric geometry but a non axi-symmetric distribution of material properties and/or loading. It is shown that analyses based on this approach can give accurate results with up to an order of magnitude saving in computer resources, compared to equivalent analyses performed with a conventional three dimensional finite element formulation.

This volume of the book (i.e Volume 2) builds on the material given in Volume 1. However, the emphasis is less on theory and more on the application of the finite element method in engineering practice. It consists of nine chapters.

Chapter 1 considers the problems involved in obtaining geotechnical parameters. These are necessary to define the constitutive models and initial conditions for an analysis. The relative merits of laboratory and field testing are discussed and the parameters that can be obtained from the various tests examined.

The analyses of tunnel construction is considered in Chapter 2. Emphasis is 
placed on simulating the construction process and how this can be achieved in a two dimensional analysis. Modelling of the tunnel lining, the choice of an appropriate constitutive model for the soil and the selection of appropriate hydraulic boundary conditions are considered.

Chapter 3 considers the analysis of earth retaining structures. In particular the analysis of gravity, embedded and reinforced/anchored walls are examined. Emphasis is placed on modelling the structural elements, choosing appropriate constitutive models and simulating construction.

Cut slopes are considered in Chapter 4 . The concepts behind progressive failure are introduced. Its role in slope stability is then examined and in particular its interaction with the long term dissipation of excess pore water pressures.

The analysis of embankments is discussed in Chapter 5 . Embankments built of earthfill and rockfill and those built on weak and strong foundations are considered. The choice of appropriate constitutive models is discussed at some length as are the appropriate hydraulic boundary conditions and the role of progressive failure. For embankments on soft ground, single and multi-staged construction and the benefits of reinforcement are examined.

Chapter 6 considers shallow foundations. To begin with, simple surface foundations are considered and comparisons with the classical bearing capacity solutions made. The ability of numerical analysis to advance the current state of the art is then demonstrated by considering some of the weaknesses in current bearing capacity theory. For example, the effect of self weight on drained bearing capacity, the effect of foundation shape and its depth below the soil surface are considered. The effects of anisotropic soil strength and of pre-loading on bearing capacity are also examined. The analysis of tall towers and the difference between bearing capacity failure and leaning instability is discussed. Analysis of the leaning Tower of Pisa is then used to demonstrate the power of numerical analysis.

Deep foundations are considered in Chapter 7. The analyses of single piles and pile groups subjected to combined vertical, lateral and moment loading are considered. The behaviour of suction caissons and the possible detrimental effects of neglecting anisotropic soil strength are discussed.

Benchmarking and validation of numerical analyses are discussed in Chapter 8. The various options, their deficiencies and results from some recent benchmarking exercises are described.

Chapter 9 describes many of the restrictions and pitfalls that the authors have experienced. In particular, restrictions implicit in modelling problems as plane strain, problems associated with initial conditions and pitfalls associated with the use of some of the more common constitutive models are discussed.

Emphasis throughout this volume of the book is placed on explaining how the finite element method should be applied and what are the restrictions and pitfalls. In particular, the choice of suitable constitutive models for the various geotechnical boundary value problems is discussed at some length. To illustrate the material presented, examples from the authors experiences with practical geotechnical problems are used. 
All the numerical examples presented in both this volume and Volume 1 of this book have been obtained using the Authors' own computer code. This software is not available commercially and therefore the results presented are unbiased. As commercial software has not been used, the reader must consider what implications the results may have on the use of such software.

London

David M. Potts

March 2001

Lidija Zdravković 


\section{Authorship}

This volume has been edited and much of its content written by David Potts and Lidija Zdravković. Several of the chapters involve contributions from colleagues at Imperial College and the Geotechnical Consulting Group (GCG). In particular:

Dr Trevor Addenbrooke (Imperial College) wrote a large part of Chapter 2 (Tunnels);

Mr Kelvin Higgins (GCG) wrote Chapter 8 (Benchmarking) and contributed to Chapter 3 (Earth retaining structures);

Dr Nebojša Kovačević (GCG) wrote large parts of Chapter 4 (Cut slopes) and Chapter 5 (Embankments).

\section{Acknowledgements}

We would like to acknowledge our colleagues Professors John Burland and Peter Vaughan and all the past and present research students at Imperial College, without whose interest and involvement this book would not have been possible. In particular we would like to acknowledge Dr Dennis Ganendra whose PhD work on pile groups (supervised by David Potts) forms part of Chapter 7 (Deep foundations).

David Potts

Lidija Zdravković 